\title{
Risk Factors and Prognosis of Spontaneously Ruptured Hepatocellular Carcinoma in Thailand
}

\author{
Jitrapa Kerdsuknirun1, Virunpat Vilaichone ${ }^{2}$, Ratha-Korn Vilaichone ${ }^{1,3,4 *}$
}

\begin{abstract}
Objective: Hepatocellular carcinoma $(\mathrm{HCC})$ is the fatal cancer worldwide. Spontaneously Rupture remains important complication of HCC. The incidence of spontaneous HCC rupture was high in ASEAN but limited studies were reported. The aim of this study was to evaluate predictors and overall survival of ruptured HCC in tertiary care center in Thailand. Methods: We conducted a retrospective cohort study of HCC patients aged $\geq 15$ years old during January 2012-January 2016 and followed up through June 2016 at Thammasat University Hospital, Thailand. All clinical information, laboratory and radiologic findings were collected from reviewing computer data base of medical records. Results: 333 patients had completely retrievable information. Of which, 51patients (15.3\%) had spontaneous ruptured HCC. Clinical symptoms with abdominal discomfort and anemic symptoms were significantly higher in ruptured than non-ruptured HCC groups. (76.47\% vs.39.36\%: p<0.001, 13.73vs.0.71\%, p <0.001). Furthermore, size of tumors, presences of metastasis and serum AFP $>200 \mathrm{ng} / \mathrm{mL}$ were significantly higher in ruptured than non-ruptured HCC groups $(10.29 \mathrm{~cm}$. vs. $6.47 \mathrm{~cm}$. $\mathrm{p}<0.001,17.65 \%$ vs. $8.16 \%, \mathrm{p}=0.034,60.78 \%$ vs. $36.88 \%, \mathrm{p}=0.001$, respectively). In multivariate analysis, age, abdominal discomfort, anemic symptoms, Child-Pugh score $>6$ were independent risk factors of $\mathrm{HCC}$ rupture $(\mathrm{OR}=0.96,95 \% \mathrm{CI}=0.93-0.99, \mathrm{p}=0.02 ; \mathrm{OR}=3.47,95 \% \mathrm{CI}=1.26-9.6, \mathrm{p}=0.016 ; \mathrm{OR}=54.51$, $95 \% \mathrm{CI}=7.09-418.89, \mathrm{p}<0.001 ; \mathrm{OR}=2.62,95 \% \mathrm{CI}=1.09-6.31, \mathrm{p}=0.031$, respectively). 1-year and 2-year survival rates of ruptured HCC were $66.9 \%$ and $44.6 \%$ respectively. Conclusions: Age, abdominal discomfort, anemic symptoms and Child-Pugh score $>6$ might be predictive factors of spontaneous ruptured HCC. Ruptures of HCC remained a fatal disease with poor survival rate in Thailand. Appropriate treatment in early stage could be effective tool to improve the treatment outcomes
\end{abstract}

Keywords: Hepatocellular carcinoma- Ruptured- Thailand

Asian Pac J Cancer Prev, 19 (12), 3629-3634

\section{Introduction}

Hepatocellular carcinoma (HCC) is the sixth most common cancer and leads to the third cancer-related death worldwide (El-Serag, 2011), thus remaining a significant health problem especially in Asian and sub-Saharan African countries (Pourhoseingholi and Zali, 2010; Wang et al., 2015; Loho et al., 2016; Kaneko et al., 2017; Chuncharunee and Siramolpiwat, 2017; Tunissiolli et al., 2017). In Thailand, HCC is the most common cancer in men and the third most common cancer in women (Somboon et al., 2014). The patients with HCC mostly have underlying chronic liver disease including liver cirrhosis (Bosch et al., 2005). The incidence of HCC is increasing in several developing countries, including Thailand and its dominant causes were related to hepatitis $B$ virus, hepatitis $C$ virus infection and alcoholic cirrhosis (Chunlertrith et al., 2000, Wiangnon et al., 2012; Liang et al., 2013; Wanich et al., 2016).

One of the life-threatening complications of HCC is the spontaneous rupture of the tumor. Spontaneous rupture of HCC occurs in 3\%-26\% of all patients with HCC and the mortality rates are high approximately 32\%-66.7\% (Liu et al., 2001; Tan et al., 2006; Miyoshi et al., 2011). The prognosis of patients with ruptured HCC was poorer compared with those without ruptured HCC. The 1-year, 3 -year and 5-year survival rates of patients with ruptured HCC were $54.2 \%, 35 \%$, and $21.2 \%$, and those of patients without ruptured $\mathrm{HCC}$ were $72.1 \%, 47.3 \%$ and $33.9 \%$ (Yeh et al., 2002). A median survival of 1.2-4 months in patients with untreated ruptured HCC was reported (Al-Mashat et al., 2002). The available treatments of ruptured HCC are hepatic resection, transcatheter arterial embolization (TAE) and conservative treatment (Rossetto et al., 2010). The most appropriate treatment is controversial and largely dependent on general conditions of the patients and

${ }^{1}$ Gastroenterology Unit, Department of Medicine, Faculty of Medicine, Thammasat University Hospital, ${ }^{2}$ Patumwan Demonstration School, Srinakharinwirot University, Bangkok, ${ }^{3}$ Gastric Cancer and Gastrointestinal Diseases Research Center, ${ }^{4}$ Department of Medicine, Chulabhorn International College of Medicine (CICM) at Thammasat University, Pathumthani, Thailand. *For Correspondence: Vilaichone@hotmail.co.th 
compensation of the underlying cirrhosis (Yoshida et al., 2016). In selected patients, timely surgical resection can result in good prognosis and long-term survival (Tarantino et al., 2011). TAE, an alternative choice of treatment, can effectively induce hemostasis with success rates of 53\%-100\% (Yoshida et al., 2016).

However, there are few reports of predictors for spontaneous rupture of $\mathrm{HCC}$ and overall survival rate especially in ASEAN. Aim of this study was to evaluate predictors and overall survival of ruptured $\mathrm{HCC}$ in Thailand.

\section{Materials and Methods}

From January 2012 to January 2016, 371 patients were diagnosed with HCC and visited Thammasat University Hospital. Among them, 333 patients (89\%) had completely retrievable information. All the clinical information, laboratory and radiologic findings of these 333 patients were successfully reviewed.

HCC was diagnosed by one typical radiologic imaging examination showing characteristic features of HCC, or two different radiologic imaging examinations to confirm characteristic features of HCC, or by histology confirmation of HCC. Ruptured HCC was diagnosed by the identification of HCC with hemoperitoneum, surrounding perihepatic hematoma, active extravasation of contrast materials, tumor protrusion from the hepatic surface, focal discontinuity of the hepatic surface or an enucleating sign from high-quality imaging (Kim et al., 2008).

The patients were divided into those with and without ruptured HCC. Data including demographics, clinical presentations, laboratory findings and overall survival were compared between 2 groups. The study was conducted according to the good clinical practice guideline and was approved by ethics committee of Thammasat University Hospital, Pathumthani, Thailand.

\section{Statistical analysis}

Continuous data were reported as mean and standard deviation, and compared by the Student $t$ test or by the Mann Whitney U test where appropriate. Discontinuous data were reported as percentage and compared by the Chi-squared test or Fisher's exact test where appropriate. The Probability of survival curves were obtained by the Kaplan-Meier method and compared by the log-rank test. The survival period was defined as the length of time from the onset of the diagnosis of HCC to the death of the patient or the closing date of the study. The closing date for the study was June 30, 2016. Multivariate analyses were performed using Cox regression model. Differences were considered significant at 0.05 . All analyses were performed by using SPSS Statistics version 23.0 (IBM Corp., Armonk, NY)

\section{Results}

Clinical characteristics of patients

A total of 371 patients with HCC, there were 333 patients had completely retrievable information. Of the
333 patients, $79 \%$ were male and the mean age was $60 \pm 12$ years. Most of them $(99.1 \%)$ had cirrhosis. The most common causes of chronic liver disease are HBV infection (45.9\%), followed by alcohol (31.5\%) and HCV infection (23.1\%). $19.8 \%$ of them still had active alcohol drinking at diagnosis. Of all patients, $45 \%$ presented with abdominal discomfort, $35.1 \%$ presented with weight loss and $31.5 \%$ were asymptomatic. There were $48.9 \%, 45 \%$ and $5.4 \%$ of patients who had Child-Pugh A, B and C at inclusion. The mean MELD and MELD-Na scores were $11 \pm 4.9$ and $13.5 \pm 5.7$, respectively. According to BCLC staging system, HCC was diagnosed most frequently at stage B (41.7\%) with the mean of the maximum size of tumors of $7.1 \pm 5 \mathrm{~cm}$. (from $1 \mathrm{~cm}$. to $22 \mathrm{~cm}$.). Presence of metastasis was evident in $9.6 \%$ of all patients at diagnosis. Data are shown in Table 1.

Prevalence of ruptured HCC and comparison of patients with and without ruptured HCC

There were 51 patients out of 333 patients $(16.5 \%)$ who had spontaneously rupture of HCC. Abdominal discomfort (76.47\% vs. $39.36 \%, p<0.001)$, anemic symptoms $(13.73 \%$ vs. $0.71 \%, \mathrm{p}<0.001)$, peritonitis at presentation $(5.88 \%$ vs. $0 \%, \mathrm{p}<0.001)$ were more frequent in ruptured $\mathrm{HCC}$ groups. The mean age of patients with ruptured HCC were less than those without ruptured HCC (55.25 \pm 12.16 vs. $60.73 \pm 12.11$ years, $p=0.003)$. Causes of cirrhosis were not significantly different between those with and without ruptured HCC. The mean of tumor size of ruptured HCC group was significantly larger than non-ruptured HCC group $(10.29 \pm 5.7 \mathrm{~cm}$ vs. $6.47 \pm 4.7 \mathrm{~cm}, \mathrm{p}<0.001)$. The patients with ruptured HCC more likely to had metastatic disease at presentation $(17.65 \%$ vs. $8.16 \%, \mathrm{p}=0.034)$. The patients with ruptured HCC had more Child-Pugh B (60.78\% vs. $42.5 \%, \mathrm{p}=0.014)$ but less Child-Pugh A $(31.37 \%$ vs. $52.5 \%, \mathrm{p}=0.006)$ at presentation than those

Figure 1. Overall Survival

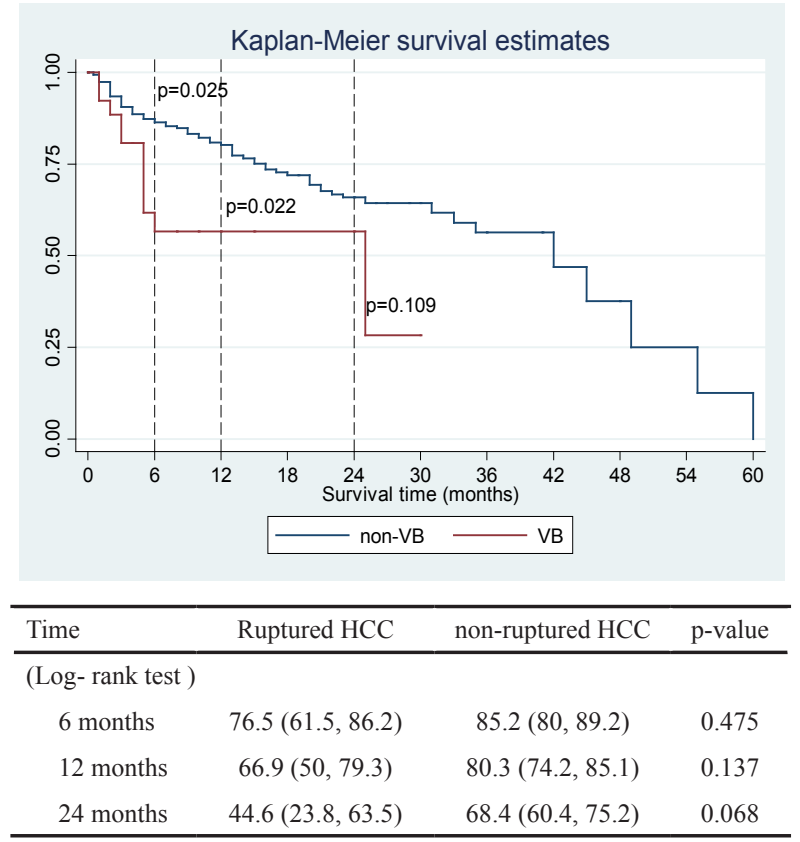

Values presented as survival probability and $95 \%$ Confident Interval (CI.). P-value corresponds to Log-rank test. 
Table 1. Demographic Data of All Patients

\begin{tabular}{|c|c|c|c|c|}
\hline & \multirow[t]{2}{*}{ Total $(n=333)$} & \multicolumn{2}{|c|}{ ruptured vs. non-ruptured $\mathrm{HCC}$} & \multirow[b]{2}{*}{ p-value } \\
\hline & & Rupture $(\mathrm{n}=\mathrm{a} 51)$ & non-rupture (n=282) & \\
\hline \multicolumn{5}{|l|}{$\overline{\operatorname{Sex}}$} \\
\hline Male & $263(79 \%)$ & $44(86.27 \%)$ & $219(77.66 \%)$ & 0.165 \\
\hline Female & $70(21 \%)$ & $7(13.73 \%)$ & $63(22.34 \%)$ & 0.165 \\
\hline Age & $59.9 \pm 12.3$ & $55.25 \pm 12.16$ & $60.73 \pm 12.11$ & 0.003 \\
\hline DM & $69(20.7 \%)$ & $11(21.57 \%)$ & $58(20.57 \%)$ & 0.871 \\
\hline \multicolumn{5}{|l|}{ Symptoms } \\
\hline asymptomatic & $105(31.5 \%)$ & $6(11.76 \%)$ & $99(35.11 \%)$ & $0.001 *$ \\
\hline abdominal discomfort & $150(45 \%)$ & $39(76.47 \%)$ & $111(39.36 \%)$ & $<0.001^{*}$ \\
\hline weight loss & $117(35.1 \%)$ & $17(33.33 \%)$ & $100(35.46 \%)$ & 0.77 \\
\hline jaundice & $9(2.7 \%)$ & $1(1.96 \%)$ & $8(2.84 \%)$ & 0.723 \\
\hline malaise/fatigue & $16(4.8 \%)$ & $3(5.88 \%)$ & $13(4.61 \%)$ & 0.696 \\
\hline anemic symptoms & $9(2.7 \%)$ & $7(13.73 \%)$ & $2(0.71 \%)$ & $<0.001^{*}$ \\
\hline GI bleed & $10(3 \%)$ & $0(0 \%)$ & $10(3.55 \%)$ & 0.371 \\
\hline fever & $8(2.4 \%)$ & $1(1.96 \%)$ & $7(2.48 \%)$ & 1 \\
\hline \multicolumn{5}{|l|}{ Physical examination } \\
\hline ascites & $11(3.3 \%)$ & $4(7.84 \%)$ & $7(2.48 \%)$ & $0.049^{*}$ \\
\hline peritonitis & $3(0.9 \%)$ & $3(5.88 \%)$ & $0(0 \%)$ & $<0.001 *$ \\
\hline hepatomegaly & $1(0.3 \%)$ & $0(0 \%)$ & $1(0.35 \%)$ & 0.67 \\
\hline splenomegaly & $2(0.6 \%)$ & $1(1.96 \%)$ & $1(0.35 \%)$ & 0.172 \\
\hline Cirrhosis & $330(99.1 \%)$ & $50(98.04 \%)$ & $280(99.29 \%)$ & 0.384 \\
\hline \multicolumn{5}{|l|}{ Cause of CLD } \\
\hline alcohol & $105(31.5 \%)$ & $17(33.33 \%)$ & $88(31.21 \%)$ & 0.764 \\
\hline $\mathrm{HBV}$ & $153(45.9 \%)$ & $25(49.02 \%)$ & $128(45.39 \%)$ & 0.632 \\
\hline $\mathrm{HCV}$ & $77(23.1 \%)$ & $8(15.69 \%)$ & $69(24.47 \%)$ & 0.171 \\
\hline NASH & $13(3.9 \%)$ & $2(3.92 \%)$ & $11(3.9 \%)$ & 0.994 \\
\hline cryptogenic & $15(4.5 \%)$ & $2(3.92 \%)$ & $13(4.61 \%)$ & 0.827 \\
\hline \multicolumn{5}{|l|}{ Risk factors } \\
\hline active alcohol & $64(19.8 \%)$ & $11(21.57 \%)$ & $55(19.5 \%)$ & 0.734 \\
\hline $\mathrm{HBeAg}+\mathrm{ve}$ & $31 / 153(20.3 \%)$ & $4(19.05 \%)$ & $27(26.73 \%)$ & 0.695 \\
\hline antiHBe +ve & $93 / 153(60.8 \%)$ & $18(85.71 \%)$ & $75(74.26 \%)$ & 0.203 \\
\hline \multicolumn{5}{|l|}{ HBV VL (cp/mL) } \\
\hline$\leq 100,000$ & $88 / 153(57.5 \%)$ & $14(66.67 \%)$ & $74(70.48 \%)$ & 0.728 \\
\hline$>100,000$ & $38 / 153(24.8 \%)$ & $7(33.33 \%)$ & $31(29.52 \%)$ & 0.728 \\
\hline CHC S/P previous $\mathrm{Rx}$ & $11(3.3 \%)$ & $0(0 \%)$ & $11(16.18 \%)$ & 0.152 \\
\hline Cure & & $0(0 \%)$ & $5(45.45 \%)$ & 0.338 \\
\hline fail & & $0(0 \%)$ & $6(54.55 \%)$ & 0.293 \\
\hline \multicolumn{5}{|l|}{ HCC BCLC stage } \\
\hline A & $88(26.4 \%)$ & $2(3.92 \%)$ & $86(30.5 \%)$ & $<0.001^{*}$ \\
\hline $\mathrm{B}$ & $139(41.7 \%)$ & $26(50.98 \%)$ & $113(40.07 \%)$ & 0.146 \\
\hline $\mathrm{C}$ & $70(21 \%)$ & $14(27.45 \%)$ & $56(19.86 \%)$ & 0.221 \\
\hline $\mathrm{D}$ & $36(10.8 \%)$ & $9(17.65 \%)$ & $27(9.57 \%)$ & 0.088 \\
\hline Mean of max. size of mass $(\mathrm{cm})$ & $7.1 \pm 5(1-22)$ & $10.29 \pm 5.7$ & $6.47 \pm 4.68$ & $<0.001^{*}$ \\
\hline Major vessel thrombosis & $75(22.5 \%)$ & $15(57.69 \%)$ & $60(71.43 \%)$ & 0.201 \\
\hline Metastasis & $32(9.6 \%)$ & $9(17.65 \%)$ & $23(8.16 \%)$ & $0.034 *$ \\
\hline \multicolumn{5}{|l|}{ Child-Pugh score } \\
\hline A & $163(48.9 \%)$ & $16(31.37 \%)$ & $147(52.5 \%)$ & $0.006^{*}$ \\
\hline B & $150(45 \%)$ & $31(60.78 \%)$ & $119(42.5 \%)$ & $0.014 *$ \\
\hline $\mathrm{C}$ & $18(5.4 \%)$ & $4(7.84 \%)$ & $14(5 \%)$ & 0.403 \\
\hline
\end{tabular}


Table 1. Continued

\begin{tabular}{|c|c|c|c|c|}
\hline & \multirow[t]{2}{*}{ Total $(n=333)$} & \multicolumn{2}{|c|}{ ruptured vs. non-ruptured HCC } & \multirow[b]{2}{*}{$\mathrm{p}$-value } \\
\hline & & $\begin{array}{l}\text { Rupture } \\
(\mathrm{n}=\mathrm{a} 51)\end{array}$ & $\begin{array}{l}\text { non-rupture } \\
\quad(\mathrm{n}=282)\end{array}$ & \\
\hline MELD score & $11 \pm 4.9$ & $11.86 \pm 4.21$ & $10.83 \pm 5.05$ & 0.171 \\
\hline MELD Na score & $13.5 \pm 5.7$ & $14.59 \pm 5.14$ & $13.26 \pm 5.77$ & 0.124 \\
\hline \multicolumn{5}{|l|}{ Signs of PHT } \\
\hline no & $216(64.9 \%)$ & $24(47.06 \%)$ & $192(68.33 \%)$ & $0.004 *$ \\
\hline controlled & $110(33 \%)$ & $27(52.94 \%)$ & $83(29.54 \%)$ & $0.001 *$ \\
\hline refractory & $6(1.8 \%)$ & $0(0 \%)$ & $6(2.14 \%)$ & 0.293 \\
\hline varices & $138(41.4 \%)$ & $15(29.41 \%)$ & $123(43.77 \%)$ & 0.058 \\
\hline splenomegaly & $180(54.1 \%)$ & $23(45.1 \%)$ & $157(55.87 \%)$ & 0.163 \\
\hline \multicolumn{5}{|l|}{ Laboratory tests } \\
\hline WBC (109/L) & & $8723.53 \pm 4092.66$ & $7390.43 \pm 4608.74$ & 0.054 \\
\hline Hct $(\%)$ & & $35.24 \pm 7.22$ & $51.64 \pm 260.87$ & 0.654 \\
\hline Plt (109/L) & $183.7 \pm 110.1$ & $226.92 \pm 130.83$ & $175.88 \pm 104.32$ & $0.002 *$ \\
\hline $\mathrm{Cr}(\mathrm{mg} / \mathrm{dL})$ & & $1.19 \pm 0.69$ & $1.11 \pm 0.85$ & 0.521 \\
\hline AST (U/L) & & $187.33 \pm 207.69$ & $108.95 \pm 123.47$ & $0.011^{*}$ \\
\hline ALT (U/L) & & $82.84 \pm 65.28$ & $73.15 \pm 47.76$ & 0.315 \\
\hline ALP (U/L) & & $186.59 \pm 111.78$ & $187.95 \pm 128.52$ & 0.944 \\
\hline TB (mg/dL) & $1.9 \pm 3.6$ & $2.18 \pm 3.35$ & $1.82 \pm 3.68$ & 0.507 \\
\hline Alb (g/dL) & & $2.5 \pm 0.55$ & $2.43 \pm 0.49$ & 0.379 \\
\hline INR & & $1.22 \pm 0.22$ & $1.61 \pm 5.98$ & 0.644 \\
\hline \multicolumn{5}{|l|}{$\operatorname{AFP}(\mathrm{ng} / \mathrm{mL})$} \\
\hline $0-20$ & $120(36 \%)$ & $12(23.53 \%)$ & $108(38.3 \%)$ & $0.043 *$ \\
\hline $20.1-200$ & $78(23.4 \%)$ & $8(15.69 \%)$ & $70(24.82 \%)$ & 0.156 \\
\hline$>200$ & $135(40.5 \%)$ & $31(60.78 \%)$ & $104(36.88 \%)$ & $0.001^{*}$ \\
\hline
\end{tabular}

Values presented as frequency (\%) and mean \pm SD. P-value corresponds to Independent's t test (Continuous data) and Chi square test or Fisher's exact test (Categorical data).

without ruptured HCC. The mean MELD scores were not different between 2 groups. Serum total bilirubin, INR, albumin, Creatinine were also not different between those with and without ruptured HCC. Serum AFP $>200$ were found more frequently in patients with ruptured HCC $(60.78 \%$ vs. $36.88 \%, p=0.001)$ as in table 1 .
Predictors for spontaneous rupture of HCC and Overall survival of patients

By multivariate cox'regression analysis, age, abdominal discomfort, anemic symptoms, Child-Pugh scores $>6$ at presentation were independently associated with spontaneously rupture of HCC (Table 2).

Overall survival of patients with ruptured $\mathrm{HCC}$ at 6-months, 12-month, and 42-month were $76.5 \%, 66.9 \%$,

Table 2. Predictive Factors for Ruptured HCC

\begin{tabular}{|c|c|c|c|c|}
\hline & \multicolumn{2}{|c|}{ Univariate analysis } & \multicolumn{2}{|c|}{ Multivariate analysis } \\
\hline & Crude OR & p-value & Adjusted OR (95\%CI) & p-value \\
\hline Male & $1.81(0.76,4.98)$ & 0.165 & & \\
\hline Age & $0.96(0.94,0.99)$ & $0.004^{*}$ & $0.96(0.93,0.99)$ & $0.02 *$ \\
\hline \multicolumn{5}{|l|}{ Symptoms } \\
\hline abdominal discomfort & $5.01(2.43,10.93)$ & $<0.001 *$ & $3.47(1.26,9.6)$ & $0.016^{*}$ \\
\hline anemic symptoms & $22.27(4,222.79)$ & $<0.001 *$ & $54.51(7.09,418.89)$ & $<0.001 *$ \\
\hline Cirrhosis & $0.36(0.02,21.49)$ & 0.384 & & \\
\hline \multicolumn{5}{|l|}{ Child-Pugh score } \\
\hline $\mathrm{B}, \mathrm{C}$ & $2.42(1.28,4.57)$ & $0.007^{*}$ & $2.62(1.09,6.31)$ & $0.031 *$ \\
\hline \multicolumn{5}{|l|}{ Signs of PHT } \\
\hline ascites & $2.43(1.33,4.44)$ & $0.004 *$ & $0.96(0.43,2.14$ & 0.925 \\
\hline
\end{tabular}

Values presented as Odds ratio (OR) and 95\% Confident Interval (CI.). P-value corresponds to Logistic regression analysis. 
$44.6 \%$, respectively. Overall survival of patients with ruptured HCC at 6-months, 12-month, and 24-month were $76.5 \%, 66.9 \%, 44.6 \%$, respectively as shown in Figure 1. .

\section{Discussion}

Spontaneous rupture of $\mathrm{HCC}$ is one of fatal complications of HCC leads to high mortality of 32\%-66.7\% (Liu et al., 2001; Tan et al., 2006; Miyoshi et al., 2011). The prognosis of patients with ruptured $\mathrm{HCC}$ was poorer compared with those without ruptured HCC with 1-year,3-year and 5-year survival rates of $54.2 \%, 35 \%$ and $21.2 \%$ vs. $72.1 \%, 47.3 \%$ and $33.9 \%$ in those without ruptured HCC (Yeh et al., 2002). A median survival of 1.2-4 months in patients with untreated ruptured HCC was reported (Al-Mashat et al., 2002). The primary goal of management for ruptured HCC is hemostasis control. Hemostasis could be done by TAE or surgery (Intaraprasong et al., 2016). TAE has a high success rate of 53\%-100\% (Yoshida et al., 2016). For the definitive treatment, staged liver resection has a good survival rate (1-year survival of $54.2 \%-100 \%$; 3-year survival of $21.2 \%-48 \%$; 5-year survival of $15 \%-21.2 \%$ ) (Lai and Lau, 2006).

Still, the mechanism of spontaneous rupture is not well understood. Hypotheses include growth of tumor and necrosis, rupture by splitting of the overlying normal hepatic parenchyma or erosion of a vessel, coagulopathy leading to initiation of spontaneous bleeding within the tumor, increasing pressure within the tumor from blockage of the branches of the hepatic veins due to cancer invasion (Ong et al., 1965; Chearanai et al., 1983). Spontaneous rupture tends to occur in large tumors, but small lesions could also rupture. Suggested mechanism was that vessels in the ruptured HCC tend to be more friable due to increased collagenase expression and increased collagen IV degradation (Zhu et al., 2001; Zhu et al., 2002).

In this study, abdominal discomfort, anemic symptoms were found more frequently in patients with ruptured $\mathrm{HCC}$ and also independently associated with rupture of HCC which was similar to other reported series (Yeh et al., 2002; Tan et al., 2006). Patients with ruptured HCC were more likely to have extrahepatic invasion or metastasis and the mean size of tumors were was larger in ruptured HCC group (10.3 \pm 5 . cm. vs. $6.5 \pm 4.7 \mathrm{~cm}$.), which were also consistent with previous study (Miyosh et al., 2011; Zhu et al., 2012). Moreover, we found that the patients with ruptured HCC had more AST elevation than those without ruptured HCC, although it's not significant. This finding were reported in previous report (Yeh et al., 2002). Various mechanisms may explain more AST elevations in ruptured HCC. AST is released by damaged cells as a consequence of increased permeability of the cell membrane or cell necrosis (Yeh et al., 2002), together with some degree of hypoxic injuries that occurs after hemorrhage and more pronounced in patients with portal venous thrombosis. Although serum alpha-fetoprotein (AFP) is shown to poorly correlate with size, stage, and prognosis of HCC (Abbasi et al., 2012; Toyoda et al., 2015). However, level of $>200 \mathrm{ng} / \mathrm{mL}$ was found more frequently in patients with ruptured $\mathrm{HCC}$ in this study.
Interestingly, age and Child-Pugh score $>6$ remained predictive for spontaneous rupture of HCC. However, the explanations of why younger patients with HCC more likely to have spontaneous rupture are still questionable. A few possible reasons were younger patients (mean age of 55 years) were at higher risk of unrecognized minor abdominal blunt trauma accompanied with coagulopathy might increase the risk of spontaneous HCC rupture. Child-Pugh scores $>6$ reflects poor liver reserve and also associated with more deficiency of clotting factors in coagulation pathway and together with platelet dysfunction (Kaul and Munoz, 2000; Tripodi et al., 2017) which consistent with previous studies that reported Child-Pugh C status was associated with poor mortality of patients with ruptured HCC (Tan et al., 2006).

In our study, the overall survival at 6 months and 12 months between patients with and without ruptured HCC was not significantly different $(76.5 \%$ vs. $85.2 \%$, $\mathrm{p}=0.475 ; 66.9 \%$ vs. $80.3, \mathrm{p}=0.137$, respectively). In our study, the overall survival at 6 months and 12 months between patients with and without ruptured $\mathrm{HCC}$ was not significantly different ( $76.5 \%$ vs. $85.2 \%, p=0.475 ; 66.9 \%$ vs. $80.3, \mathrm{p}=0.137$, respectively) which were comparable to previous studies (Tan et al., 2006).

There were limitations in this study. First, this was a retrospective study, it may have affected the quality of the data. Second, it was not a controlled study which possible confounding factors could occur, despite multivariate analysis was performed to decrease this effect. Third, emergency tumor resection for controlling the bleeding was a limited practice and not always an available option in our center. TAE was considered to be routinely preferred option of treatment for ruptured HCC. The cumulative survival in this study may not represent all cases with ruptured $\mathrm{HCC}$, because the choice of treatment which the patients received largely influence their survival rates.

In summary, spontaneously rupture $\mathrm{HCC}$ is a fatal complication of HCC leading to high mortality in this group of patients. Our study demonstrated age at diagnosis, abdominal distension, anemic symptoms, Child-Pugh scores $>6$ were independently associated with rupture of HCC. The 24-month overall survival of those with ruptured HCC was $44.6 \%$, significantly decreased compared with those without ruptured HCC. Since ruptures of HCC remain fatal disease with poor survival rate in Thailand, appropriate treatment in early stage could be effective tool to improve the treatment outcomes.

\section{References}

Abbasi A, Bhutto AR, Butt N, Munir SM (2012). Corelation of serum alpha fetoprotein and tumor size in hepatocellular carcinoma. J Pak Med Assoc, 62, 33-6.

Al-Mashat FM, Sibiany AM, Kashgari RH, et al (2002). Spontaneous rupture of hepatocellular carcinoma. Saudi Med J, 23, 866-70.

Bosch FX, Ribes J, Cleries R, Diaz M (2005). Epidemiology of hepatocellular carcinoma. Clin Liver Dis, 9, 191-211.

Chearanai O, Plengvanit U, Asavanich C, et al (1983). Spontaneous rupture of primary hepatoma. Report of 63 cases with particular reference to the pathogenesis and rationale of treatment by hepatic artery ligation. Cancer, 
51, 1532-6.

Chuncharunee A, Siramolpiwat S (2017). Validation of the Hong Kong liver cancer staging ystem in patients with hepatocellular carcinoma after curative intent treatment. Asian Pac J Cancer Prev, 18, 1697-701.

Chunlertrith K, Sukeepaisarnjaroen W, Mairiang P, et al (2000).

Clinico-epidemiology of hepatitis C viral infection in northeastern Thailand. Southeast Asian J Trop Med Public Health, 31, 273-6.

El-Serag HB (2011). Hepatocellular Carcinoma. N Engl J Med, 365, 1118-27.

Intaraprasong P, Siramolpiwat S, Vilaichone RK (2016). Advances in management of hepatocellular carcinoma. Asian Pac J Cancer Prev, 17, 3697-703.

Kaneko R, Nakazaki N, Omori R, et al (2017). The effect of new therapeutic and diagnostic agents on the prognosis of hepatocellular carcinoma in Japan - An analysis of data from the Kanagawa cancer registry. Asian Pac J Cancer Prev, 18, 2471-6.

Kaul VV, Munoz SJ (2000). Coagulopathy of liver disease. Curr Treat Options Gastroenterol, 3, 433-8.

Kim HC, Yang DM, Jin W, Park SJ (2008). The various manifestations of ruptured hepatocellular carcinoma: CT imaging findings. Abdom Imaging, 33, 633-42.

Lai EC, Lau WY (2006). Spontaneous rupture of hepatocellular carcinoma: a systematic review. Arch Surg, 141, 191-8.

Liang T, Chen EQ, Tang H (2013). Hepatitis B virus gene mutations and hepatocarcinogenesis. Asian Pac J Cancer Prev, 14, 4509-13.

Liu CL, Fan ST, Lo CM, et al (2001). Management of spontaneous rupture of hepatocellular carcinoma: single-center experience. J Clin Oncol, 19, 3725-32.

Loho IM, Hasan I, Lesmana CR, Dewiasty E, Gani RA (2016). Hepatocellular carcinoma in a tertiary Referral Hospital in Indonesia: Lack of improvement of one-year survival rates between 1998-1999 and 2013-2014. Asian Pac J Cancer Prev, 17, 2165-70.

Miyoshi A, Kitahara K, Kohya N, Noshiro H, Miyazahi K (2011). Outcomes of patients with spontaneous rupture of hepatocellular carcinoma. Hepatogastroenterology, $\mathbf{5 8}$, 99-102.

Ong GB CE, Yu FYK, Lee TC (1965). Spontaneous rupture of hepatocellular carcinoma. Br J Surg, 52, 123-9.

Pourhoseingholi MA FZ, Zali MR (2010). Burden of hepatocellular carcinoma in Iran; Bayesian projection and trend analysis. Asian Pac J Cancer Prev, 11, 859-62.

Rossetto A, Adani GL, Risaliti A, et al (2010). Combined approach for spontaneous rupture of hepatocellular carcinoma. World J Hepatol, 2, 49-51.

Somboon K, Siramolpiwat S, Vilaichone RK (2014). Epidemiology and survival of hepatocellular carcinoma in the central region of Thailand. Asian Pac J Cancer Prev, 15, 3567-70.

Tan FL, Tan YM, Chung AY, et al (2006). Factors affecting early mortality in spontaneous rupture of hepatocellular carcinoma. ANZ J Surg, 76, 448-52.

Tarantino L, Sordelli I, Calise F, et al (2011). Prognosis of patients with spontaneous rupture of hepatocellular carcinoma in cirrhosis. Updates Surg, 63, 25-30.

Toyoda H, Kumada T, Tada T, Sone Y, Kaneoka Y, et al (2015). Tumor markers for hepatocellular carcinoma: Simple and significant predictors of outcome in patients with HCC. Liver Cancer, 4, 126-36.

Tripodi A, Primignani M, Mannucci PM, Caldwell SH (2017). Changing concepts of cirrhotic coagulopathy. Am J Gastroenterol, 112, 274-81

Tunissiolli NM, Castanhole-Nunes MMU, Biselli-Chicote PM,
Pavarino EC, et al (2017). Hepatocellular carcinoma: a comprehensive review of biomarkers, clinical aspects, and therapy. Asian Pac J Cancer Prev, 18, 863-72.

Wanich N, Vilaichone RK, Chotivitayatarakorn P, Siramolpiwat S (2016). High prevalence of hepatocellular carcinoma in patients with chronic hepatitis B infection in Thailand. Asian Pac J Cancer Prev, 17, 2857-60.

Wang CH, Wey KC, Mo LR, et al (2015). Current trends and recent advances in diagnosis, therapy, and prevention of hepatocellular carcinoma. Asian Pac J Cancer Prev, 16, 3595-604.

Wiangnon S, Kamsa-ard S, Suwanrungruang K, et al (2012). Trends in incidence of hepatocellular carcinoma, 1990-2009, Khon Kaen, Thailand. Asian Pac J Cancer Prev, 13, 1065-8.

Yeh CN, Lee WC, Jeng LB, Chen MF, Yu MC (2002). Spontaneous tumour rupture and prognosis in patients with hepatocellular carcinoma. Br J Surg, 89, 1125-9.

Yoshida H, Mamada Y, Taniai N, Uchida E (2016). Spontaneous ruptured hepatocellular carcinoma. Hepatol Res, 46, 13-21.

Zhu LX, Geng XP, Fan ST (2001). Spontaneous rupture of hepatocellular carcinoma and vascular injury. Arch Surg, 136, 682-7.

Zhu LX, Liu Y, Fan ST (2002). Ultrastructural study of the vascular endothelium of patients with spontaneous rupture of hepatocallular carcinoma. Asian J Surg, 25, 157-62.

Zhu Q, Li J, Yan JJ, et al (2012). Predictors and clinical outcomes for spontaneous rupture of hepatocellular carcinoma. World J Gastroenterol, 18, 7302-7.

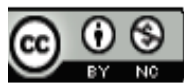

This work is licensed under a Creative Commons AttributionNon Commercial 4.0 International License. 